\title{
Dokumentasi budaya ngaruat lembur di Radio RASI FM
}

\author{
Dian Wardiana1, Ute Lies Siti Khadijah², Evi Nursanti Rukmana ${ }^{3}$ \\ ${ }^{1}$ Program Studi Jurnalistik Universitas Padjadjaran \\ 2,3Program Studi Ilmu Perpustakaan Universitas Padjadjaran \\ Jl. Raya Bandung-Sumedang Km. 21, Jatinangor, Sumedang, Jawa Barat 45363 \\ E-mail: ${ }^{1}$ d.wardiana@unpad.ac.id, 2ute.lies@unpad.ac.id, 3evi.nursanti.r@gmail.com
}

Received: January 2018; Accepted: June 2018; Published: June 2018

\begin{abstract}
Radio RASI FM is a community radio that organizes and broadcasts the tradition of 'ngaruat lembur', the tradition of expressing gratitude to God, and to ward off disasters as well. This radio performs documentation starting from data searching to creating a form of cultural documentation. The study purpose was to see the documentation process of the traditional culture of 'ngaruat lembu' at RASI FM radio. The research used the case study method through qualitative method approach to the owner, broadcaster of radio and community of Cisewu Village. The study results indicated that RASI FM radio documented the 'ngaruat lembur' tradition through the recording and management process. Recording activities started from the collection of information and records in the form of pouring data. Management activities consisted of the distribution of duties as an on-air announcer, off-air broadcaster, and audio-visual documentation. Then, the storage of written broadcast results on radio and data into audio-visual media was performed and preservation of documents through the separation and maintenance of audio-visual media. Based on that, we constructed a model of the cultural documentation process of 'ngaruat lembur' on RASI FM radio. The radio serves as a preserver of rural community traditions through the 'ngaruat lembur' program, which is followed by all circles of society. However, the radio team did not yet have a digital-based form of audio-visual documentation maintenance. Nevertheless, RASI FM radio has become a forum for transferring traditional information of Cisewu Village community.
\end{abstract}

Keywords: Cultural documentation; RASI FM; Ngaruat lembur tradition

\begin{abstract}
Abstrak
Radio RASI FM sebagai radio komunitas yang menyelenggarakan dan menyiarkan tradisi ngaruat lembur, yakni tradisi sebagai ucapan syukur pada Tuhan Yang Maha Esa dan sebagai penghalau bencana (tulak bala). Radio ini melakukan dokumentasi dari mulai pencarian data hingga membuat bentuk dokumentasi budaya. Untuk melihat hal ini, maka penelitian dilakukan untuk melihat proses dokumentasi budaya tradisi ngaruat lembur di radio RASI FM. Metode penelitian yang digunakan ialah metode studi kasus melalui pendekatan metode kualitatif pada pemilik, penyiar radio dan masyarakat Desa Cisewu. Hasil penelitian ini menunjukkan bahwa radio RASI FM mendokumentasikan tradisi ngaruat lembur melalui proses perekaman dan pengelolaan. Kegiatan perekaman dimulai dari pengumpulan informasi yang dilakukan penyiar radio sebelum kegiatan berlangsung, dan pencatatan berupa penuangan data. Kegiatan pengelolaan terdiri dari penghimpunan yang dilakukan penyiar radio dengan membagi tugas sebagai penyiar secara on-air, penyiar secara off-air dan penyiar yang mendokumentasikan audio-visual. Lalu dalam penyimpanan berupa menyimpan tulisan hasil siaran di radio dan penyimpanan data ke dalam media audio-visual, dan pelestarian dokumen melalui pemisahan dan perawatan media audio-visual. Berdasarkan hal ini, kami membuat model proses dokumentasi budaya ngaruat lembur di radio RASI FM. Radio berperan sebagai pelestari tradisi masyarakat desa melalui program ngaruat lembur yang menjadi terbuka diikuti oleh semua kalangan masyarakat. Tim radio RASI FM menjadi belajar membuka relasi dengan pelbagai masyarakat. Namun tim radio belum memiliki perawatan bentuk dokumentasi audiovisual berbasis digital. Walaupun begitu, radio RASI FM telah menjadi wadah transfer informasi tradisi masyarakat Desa Cisewu.
\end{abstract}

Kata Kunci: Dokumentasi budaya; RASI FM; Tradisi ngaruat lembur

doi: https://doi.org/10.24198/ikip.v6i1.15325

(C) 2018 Jurnal Kajian Informasi \& Perpustakaan. This is an open access article under the CC BY-SA license

Website: http://jurnal.unpad.ac.id/jkip 


\section{PENDAHULUAN}

Radio komunitas menjadi radio yang berada di masyarakat daerah yang berfungsi sebagai sarana informasi, sarana edukasi dan sarana komunikasi bagi masyarakat. Radio komunitas disingkat RAKOM, dapat menjadi wadah transfer pengetahuan ke masyarakat. Selain itu, RAKOM berperan menjadi media pembelajaran masyarakat dalam pelbagai hal, misalnya belajar mengamati sekitar. Di sinilah peran penyiar sebagai jembatan komunikasi ke pendengar melalui pesan dari program radio.

Salah satu contoh dari ketiga fungsi radio komunitas dapat berupa program kearifan lokal. Radio komunitas menjadi sarana pemelihara kebudayaan masyarakat daerah di mana radio tersebut berada. Mengenai hal ini, Lilis, Yuliati, and Rochim (2013) menjelaskan,

"Radio komunitas lahir dari perkembangan media massa elektronik ke arah kesadaran lokalit. [..] radio komunitas diartikan sebagai radio dari, oleh, untuk dan tentang komunitas. Radio ini menjadikan komunitas sebagai basis operasionalisasi radio. Karena menonjolkan unsur lokalitas ini, proses produksi dan program acara radio komunitas cenderung berbeda-beda di setiap komunitas".

Radio komunitas yang berada di satu wilayah akan berbeda dengan radio komunitas di wilayah lainnya. Misalnya radio komunitas yang berlokasi di daerah pegunungan akan menyajikan program mengenai budaya menanam padi sedangkan radio komunitas daerah pantai akan menyajikan program budaya memelihara pantai. Radio komunitas akan menyajikan siaran yang sesuai kebutuhan masyarakat daerah. Dengan demikian, radio komunitas harus mampu menjangkau masyarakat di pelosok daerah melalui program kearifan lokal yang dimiliki masyarakat.

Sedyawati (2006) dalam Sedana, Damayani and Khadijah (2013) menyatakan bahwa kearifan lokal ialah, “Kearifan dalam kebudayaan tradisional [...] yang terjabar ke dalam seluruh warisan budaya baik yang tangible maupun intangible". Kearifan lokal akan dimiliki oleh masyarakat di tiap daerah, baik yang berwujud atau tidak berwujud. Kearifan lokal yang dikatakan berwujud, contohnya aturan, nilai kehidupan, arsitektur, seni, dan petuah-petuah yang telah tercatat sedangkan yang tidak berwujud merupakan kebijakan masyarakat yang masih lisan; belum tercatat.

Salah satu radio komunitas yang memiliki program kearifan lokal tersebut ialah Radio RASI FM di Desa Cisewu, Kecamatan Cisewu, Kabupaten Garut, melalui program ngaruat lembur. Budaya ngaruat lembur (hajat lembur) merupakan tanda ucapan syukur pada Tuhan Yang Maha Esa khas Masyarakat Kecamatan Cisewu, dan sebagai simbol tolak bala (tulak bala) terhadap bencana yang akan menimpa desa. Tradisi ini setiap tahunnya selalu diselenggarakan pada penanggalan Islam di Bulan Mulud/Rabi'ul Awal. Awalnya, kegiatan ini hanya diikuti oleh beberapa orang saja. Lalu, pada Bulan April 2017, Radio RASI FM mulai mengadakan dan menyiarkan program ngaruat lembur dengan melibatkan masyarakat se-Kecamatan Cisewu.

Budaya ngaruat lembur menjadi tradisi masyarakat Desa Cisewu. Ngaruat lembur bukan berarti hanya kegiatan 
berdoa bersama saja tapi memiliki fungsi tersendiri bagi masyarakat Desa Cisewu. Dari tradisi ini, masyarakat menjadi belajar mengenai sikap menghargai alam, di mana mereka tinggal; saling mengeratkan diri satu sama lain untuk saling menjaga; dan masyarakat menyadari untuk menjadi diri yang lebih baik.

Ketiga hal di atas, telah tercipta melalui program ngaruat lembur yang diadakan selama dua hari di Desa Cisewu. Hari pertama diselenggarakannya upacara seren taun di Kecamatan Cisewu dan hari kedua acara seni budaya di Balong Sirah Desa Cisewu. Radio RASI FM menyelenggarakan dan menyiarkan program ngaruat lembur secara on-air dan off-air sebagai bentuk kepedulian radio dalam menjaga budaya Kecamatan Cisewu. Ketua radio menjelaskan, "Karena kepedulian terhadap lingkungan dan kepedulian terhadap seni budaya anu memang bagian nu padam (yang mati), mati mah henteu (tidak mati), cuman redup" (Latif, wawancara, September 6, 2017). RASI FM menjadi media komunikasi di antara sesama masyarakat, masyarakat terhadap lingkungan dan budayanya.

Budaya ngaruat lembur mulai diadakan di Desa Cisewu setelah desa ini pernah mengalami musim paceklik yang lama. Selain itu, satu gunung hancur akibat pengerukan tanah yang mengakibatkan struktur tanah desa mengalami pergeseran dan bahkan merusak mata air. Masyarakat Desa Cisewu menjadi tergerak untuk bersama-sama menjaga kekayaan alam di desa dan bersama-sama berdoa meminta perlindungan pada $\mathrm{Tu}$ han Yang Maha Esa.

Budaya ini tak hanya dilakukan di Deca Cisewu saja. Beberapa desa atau kampung adat masih melakukan tradisi ngaruat lembur. Salah satunya kampung adat Cikondang, Desa Lamajang, Kecamatan Pangalengan, Kabupaten Bandung, yang masih melakukan tradisi ngaruat lembur (hajat lembur) sebagai ungkapan pengelolaan kampung (Ramdhan, 2015). Namun, tradisi ini menjadi unik ketika satu radio komunitas berperan penting dalam mendokumentasikan dan mengajak semua orang ikut berpartisipasi, termasuk Desa Cisewu.

Peran radio komunitas RASI FM dalam mengembangkan budaya masyarakat sesuai fungsi radio komunitas dari Frasser dan Estrada (2001) dalam Desideria (2012), bahwa salah satu poinnya menyatakan, kalau radio komunitas berfungsi mempromosikan dan mendukung identitas, karakter dan budaya lokal. Ini sesuai visi radio RASI FM yang menjadikan Desa Cisewu sebagai komunitas yang cerdas dan terorganisir. Masyarakat Desa Cisewu mampu menggunakan informasi kebencanaan dari radio untuk membantu menjaga kekayaan alam desa dan menyadarkan untuk menjaganya bersama-sama. Membangun rasa kebersamaan ini yang terus diusung radio sebagai wadah dialog masyarakat dalam menggali kearifan lokal di budaya Sunda.

Susanti, Mulyana, and Damayani (2013) menjelaskan bahwa, "Pola kebiasaan yang dilakukan oleh suku Sunda dalam memahami dan menempatkan diri dalam kehidupan disebut budaya Sunda". Masyarakat Sunda yang telah memiliki aturan tersendiri dalam menjalani kehidupan dapat dikatakan sebagai budaya Sunda. Tata nilai atau aturan tersebut telah mengakar dan ada waktu-waktu tertentu sebagai hari yang sakral. 
Salah satu budaya Sunda tersebut, ialah program ngaruat lembur yang diadakan dan disiarkan RASI FM sebagai bentuk dokumentasi budaya masyarakat Cisewu. Radio ini telah melakukan pengumpulan informasi, penghimpunan dan pemilihan, penyelenggaraan kegiatan dan penyimpanan data sebagai dokumentasi mengenai budaya ngaruat lembur di Desa Cisewu. RASI FM dalam melakukan dokumentasi budaya menjadi hal yang menarik. Pertama, radio komunitas adalah radio swadaya, tanpa memungut bayaran pada masyarakat. Kedua, radio ini mampu menjangkau masyarakat Desa Cisewu sampai dusun terpencil melalui ngaruat lembur. Ketiga, masyarakat dari pelbagai kalangan menjadi berbaur dalam tradisi ngaruat lembur.

Apalagi, radio RASI FM menjadi pengubung suara masyarakat dengan pemerintah daerah. RASI FM menjadi penyalur aspirasi masyarakat untuk terus melestarikan tradisi ngaruat lembur pada pemerintah, sehingga pemerintah mengapresiasinya melalui pemberian bantuan secara moril dalam penyelenggaraan kegiatan ini. Selain itu, pemerintah bekerja sama dengan para budayawan melalui radio untuk terus mendiseminasikan informasi mengenai penyelenggaraan tradisi ini setiap tahunnya pada masyarakat.

Berdasarkan latar belakang di atas, radio RASI FM menjadi jembatan transfer informasi melalui penyelenggaraan program ngaruat lembur. Tapi, jika program ini tidak terdokumentasikan dengan baik maka catatan sejarah ngaruat lembur akan makin berkurang. Mereka telah mendokumentasikan program ngaruat lembur melalui perlengkapan radio yang sederhana dan kru radio yang hanya dari penduduk sekitar. Untuk itu, ini menjadi fenomena menarik untuk diteliti untuk mengetahui bagaimana kegiatan dokumentasi budaya ngaruat lembur yang dilakukan radio RASI FM.

Sudarsono (2016) menyatakan bahwa dokumentasi terdiri dari dua kegiatan, "merekam dan mengelola". Kegiatan merekam ialah merekam pengetahuan yang belum terekam dari sebuah pemikiran, proses kerja, peristiwa dan pengetahuan. Kegiatan mengelola ialah menghimpun pengetahuan yang sudah terekam berupa tulisan, suara citra objek analog dan digital. Dari dua kegiatan ini terintegrasi menjadi suatu wadah atau media sebagai sistem temu kembali informasi.

Bila dihubungkan dalam penelitian ini, program ngaruat lembur merupakan pengetahuan yang belum terdokumentasikan atau pengetahuan yang belum terekam. Pada awalnya ngaruat lembur berawal dari budaya lokal masyarakat yang dilakukan tiap tahun oleh kalangan tertentu tanpa ada bukti catatan, foto atau rekaman mengenai kegiatan ini. Maka, dokumentasi program ngaruat lembur berawal dari kegiatan merekam pengetahuan budaya lokal lalu dikelola menjadi media cetak dan elektronik. Dari dua kegiatan ini terbentuknya suatu wadah sebagai database informasi.

Proses merekam dapat digolongkan ke dalam "self-documentation" (Whitaker \& Mancini, 2013). Yakni kegiatan dokumentasi yang berawal dari mengumpulkan informasi yang ada lalu mencatat. Subjek atau manusia menjadi sumber informasi yang digali dari pelbagai hal. Objek yang didokumentasikan dalam penelitian ini ialah budaya ngaruat lembur. Budaya "Bukan merupakan benda namun aturan bagaimana manusia 
hidup" (Kusumohamidjojo, 2009). Aturan manusia dapat diperoleh dari bentuk catatan dan lisan. Tradisi ngaruat lembur ini sendiri, diperoleh berupa bentuk lisan dari penduduk lokal.

Tradisi lisan suatu daerah menandakan proses komunikasi yang sedang berlangsung di daerah tersebut. Di mana, "The oral history interview, and acknowledges the value of local knowledge" (Baron, 2016). Tradisi menandakan adanya keberulangan dan pertukaran informasi, kebiasaan dan ekspresi verbal dari kelompok atau masyarakat. Adanya pengetahuan yang dilakukan dulu lalu sekarang diulang kembali atau pengetahuan yang ditransfer dari kelompok di wilayah yang sama. Pengetahuan ini menyiratkan nilai pembelajaran dan identitas dari wilayah tersebut. Tradisi ngaruat lembur di Desa Cisewu bisa dikatakan pengetahuan tulak bala (tolak bala) yang ditransfer masyarakat dulu ke masyarakat sekarang atau transfer pengetahuan dari orang ke orang di sekitar Desa Cisewu karena belum ada bukti catatan tertulis mengenai tradisi ini. Selain itu, Erwina, Kusnandar and Samson (2013) dalam CMS (2018) menambahkan bahwa dokumentasi budaya sebagai,

“Prinsip dan teknik
penyusunan, penyimpanan,
temu balik, pemencaran serta
evaluasi informasi terekam yang
berkaitan dengan hasil cipta,
karsa dan rasa manusia, baik ke-
budayaan material maupun im-
material yang tersimpan dalam
berbagai medianya".
Dari pengertian ini dapat terlihat
bahwa dalam dokumentasi budaya, peneliti harus mengumpulkan data, menyusun lalu mendiseminasikan informasi.
Dalam pengumpulan data, peneliti mencari data melalui sumber primer, dan sekunder. Sumber primer diperoleh dari budaya ngaruat lembur dari sumber lisan (folklor). Sumber sekunder diperoleh dari narasumber pendukung yang mengetahui tradisi ini, misalnya budayawan dan masyarakat sekitar. Maka, hasil observasi lapangan diceritakan sesuai temuan di lapangan lalu kami analisis.

Satu penelitian mengenai dokumentasi budaya kearifan lokal di masyarakat ialah mengenai tradisi hajat lembur. Dijelaskan bahwa,

“Tradisi hajat lembur di Tatar Karang Priangan merupakan sumber belajar terpadu, dengan memperhitungkan unsur etik dan estetik, yang menyeimbangkan antara kognisi, afeksi dan psikomotorik, diyakini, dihayati, dan dilakukan (perilaku) serta dilaksanakan hingga saat ini" (CMS, 2018).

Tradisi berbasis kearifan lokal ternyata bukan hanya mengulang kebiasaan masyarakat yang sebelumnya dilakukan namun memiliki tujuan mengembangkan masyarakat dari segi kognisi, afeksi dan psikomotriknya. Secara tidak langsung, tradisi telah membantu memberdayakan masyarakat dari segala segi. Dalam tradisi ngaruat lembur di Desa Cisewu pun begitu. Masyarakat belajar menghargai alam dan menghargai dirinya sendiri.

Setelah kegiatan merekam, catatan yang berisi informasi lalu dikelola melalui penghimpunan, penyimpanan dan pelestarian dokumen. Encyclopedic Dictionary of Library Science and Information Technology, Vol.1 dalam Purwono menjelaskan bahwa dokumentasi menunjuk pada "[..] ilmu 
pengumpulan, penyimpanan, pengorganisasian rekaman bahan informasi atau dokumen agar dapat diakses secara optimal [..]" (Purwono, 2010). Kegiatan penghimpunan di sini ialah mengumpulkan pengetahuan yang sudah tercipta dan yang belum tercipta. Kegiatan penyimpanan adalah proses simpan dokumentasi yang telah mengalami pelabelan dan adanya pengorganisasian informasi. Kegiatan pengorganisasian ialah sarana temu kembali informasi bentuk dokumentasi agar informasinya digunakan pengguna. Terakhir, pelestarian dokumen berupa pengawetan dan perbaikan dokumen. Hasil analisis ini semoga dapat menjadi rujukan pelaksanaan kegiatan dokumentasi budaya dalam program budaya lokal di radio komunitas di tiap daerah, yang memiliki keanekaragaman dalam budayanya.

\section{METODE PENELITIAN}

Penelitian ini menggunakan metode penelitian kualitatif, yakni metode penelitian yang mencoba mengangkat fenomena di masyarakat. Masyarakat menjadi subjek kajian yang menarik untuk diteliti. Kehidupan masyarakat memiliki sisi yang khas atau unik, misalnya dari perilaku, motivasi, dan lingkungan. Namun, hal ini perlu dianalisis lebih jauh untuk alasan dan bagaimana hal tersebut tercipta di masyarakat. Jadi, penelitian kualitatif merupakan metode penelitian yang mampu menggambarkan lebih mendalam dan menginterpretasikan mengenai masalah atau fenomena di masyarakat melalui uraian kalimat.

Metode studi kasus dalam metode penelitian kualitatif ialah pendekatan yang mengidentifikasi pertanyaan penelitian yang menjadi topik penelitian. Merriam-Webster Dictionary's (2009) dalam Harrison, Birks, Franklin, and Mills (2017) lebih menjelaskan, "An intensive analysis of an individual unit (as a person or community) stressing developmental factors in relation to environment". Dalam studi kasus, individu sebagai subjek penelitian diamati lalu dianalisis untuk melihat fenomena yang sedang dihadapinya.

Selain itu, melalui studi kasus, Stake (2006) dalam Harrison et al. (2017) menyatakan,

"A case or cases are selected for what they can reveal about topic of interest and depend on the aim and conditions of the study. A case is selected because it is interesting in itself or can facilitate the understanding of something else; it is instrumental in providing insight on an issue".

Peneliti harus memilih kasus atau fenomena yang menurutnya menarik dan sesuai kajian studi yang sedang ditelitinya. Dalam menemukan kasus, peneliti harus memiliki rasa katertarikan untuk mendalami kasus tersebut, untuk memudahkan dalam pemahaman dan menggali hal-hal yang berkaitan terhadap kasus tersebut.

Berdasarkan penelitian studi kasus, pertanyaan penelitian menjadi kunci dalam membuktikan fenomena yang sedang diamati. Peneliti terus mencari data yang berkaitan hingga menemukan jawaban yang lengkap atas pertanyaan penelitian. Peneliti dalam menggunakan sumber pencarian data menjadi kekuatan dan kelemahan dalam membuktikan data. Begitupun dalam penelitian ini. Fenomena pendokumentasian budaya ngaruat lembur memiliki sisi yang menarik untuk 
diketahui jawaban dari pertanyaan penelitian melalui pemilik dan penyiar radio, dan masyarakat Desa Cisewu yang ikut berpartisipasi dalam penyelenggaraan program ngaruat lembur. Selain itu, pertama, radio RASI FM mendokumentasikan ngaruat lembur melalui cara mengadakan kegiatan dan membuat hasil dokumentasinya. Kedua, budaya ngaruat lembur memperlihatkan identitas Desa Cisewu dalam melindungi kemanan desa dari bencana.

Peristiwa yang diteliti hanya mengenai dokumentasi budaya ngaruat lembur yang kami teliti pada September 2017. Kami menggolongkan fenomena ini menjadi studi kasus tunggal atau single case. Hasil analisis ini, menggambarkan dokumentasi budaya ngaruat lembur yang dilakukan radio RASI FM dan memperlihatkan peran radio sebagai pemelihara budaya lokal.

Mengacu pendapatnya Stake (2006) dalam Harrison et al. (2017), bahwa peneliti dalam penelitian studi kasus perlu menggunakan sumber pencarian data yang tepat. "Multiple sources and methods of data collection and analysis can be used, however, interviews and observations are the preferred and dominant data collection method". Peneliti dapat menggunakan semua sumber dan metode pengumpulan data jika metode yang digunakannya dikuasai oleh peneliti. Selain itu, peneliti harus mengerti apa yang dikatakan narasumber, apa yang mereka lihat, apa yang mereka hasilkan, apakah dokumen dan rekaman lainnya. Untuk itu, peneliti dapat menggunakan 6 sumber pencarian data dalam memudahkan penelitian, "Documents, records, interviews, 'detached' observations, participant observations, physical artefacts" (Harrison et al., 2017).
Bila disimpulkan, kami membaginya menjadi tahap persiapan, tahap pelaksanaan dan tahap akhir. Tahap persiapan ialah penyiapan rencana penelitian dan rujukan yang berkaitan, terdiri dari documents dan records. Sumber informasi dari documents, merupakan dokumen berkaitan yang digunakan dalam membuat surat perijinan penelitian di Desa Cisewu, regulasi penyiaran radio komunitas, standar penyiaran, catatan kegiatan ngaruat lembur di radio RASI FM dan tinjauan literatur. Melalui tinjauan literatur dapat memberikan pandangan yang luas mengenai tema yang sedang dikaji. Dalam penelitian ini, literatur yang digunakan dari beberapa buku mengenai dokumentasi, budaya dan literatur mengenai pendekatan studi kasus. Sumber informasi dari records, merupakan rekaman hasil siaran kegiatan ngaruat lembur oleh radio RASI FM.

Tahap pelaksanaan ialah peneliti mulai mencari data untuk menjawab pertanyaan penelitian melalui interviewes, observations, participant observations dan physical artefacts. Dalam sumber informasi melalui interviewes, peneliti melakukan wawancara informal pada narasumber. Narasumber terdiri dari pemilik radio dan penyiar radio RASI FM, dan masyarakat yang ikut berpartisipasi dalam kegiatan ngaruat lembur. Transkrip wawancara yang berbentuk kutipan menjadi pelengkap atau menambah originalitas penelitian.

Dalam observation, peneliti melakukan explanatory description, menggambarkan apa yang dilihat lebih mendalam. Peneliti berkunjung langsung ke radio RASI FM dan melihat proses pendokumentasian kegiatan ngaruat lembur di Desa Cisewu. Selain itu, dalam 
melakukan observation, peneliti berperan sebagai participant observation. Peneliti ikut berperan sebagai peserta kegiatan ngaruat lembur di Desa Cisewu. Dalam physical artefacts, peneliti mencari hasil fotografi yang dilakukan radio RASI FM dalam kegiatan tersebut.

Tahap akhir ialah konfirmasi hasil temuan di lapangan (confirming case study findings). Sumber data lalu dikonfirmasi atau diteliti kembali kebenarannya. Peneliti menanyakan hal ini pada subjek penelitian lalu kembali mengkaitkannya ke dalam tinjauan literatur.

\section{HASIL DAN PEMBAHASAN}

Pertama kalinya, radio RASI FM menggelar budaya ngaruat lembur bulan April 2017 pada penanggalan Islam tanggal 14 dan 15 Bulan Mulud. Acara yang terdiri dari dua hari ini berupa acara seren taun dan upacara ngaruat lembur. Upacara seren taun berupa pertunjukan kurang lebih 20 kesenian tradisional mulai dari permainan calung, gègèl jubleug dan permainan tradisional yang dimiliki masyarakat Desa Cisewu pada hari pertama dan hari kedua. Upacara ngaruat lembur yang dimulai dari Pkl. 23.30 hingga 00.00 dilakukan pada hari kedua.

Upacara seren taun merupakan tradisi penyerahan hasil bumi masyarakat. Nuryaman (2017) menceritakan bahwa budaya seren taun selalu digelar masyarakat Sunda, misalnya di Masyarakat Adat Sunda Wiwitan, Kabupaten Kuningan. Dalam budaya seren taun, masyarakat membawa hasil bumi yang terdiri dari padi dan umbi-umbian untuk dikumpulkan lalu disimpan dalam tempat penyimpanan pangan milik desa.

Untuk memeriahkan kegiatan seren taun, dan menarik semua orang untuk berpartisipasi maka diadakan pertunjukan khas dan permainan tradisional di masyarakat. Di Desa Cisewu pun seperti itu. Salah satunya ialah pertunjukkan gègèl jubleug. Beberapa orang yang telah memiliki keahlian atau kemampuan dalam pertunjukkan ini, menggigit jubleug, yakni alat menumbuk padi, melalui giginya langsung tanpa alat bantu. Dari hal ini, memperlihatkan bahwa jubleug erat kaitannya dengan padi, bahwa padi dapat dimanfaatkan manusia jika telah mengalami proses penumbukkan dalam jubleug. Padi menjadi pangan pokok masyarakat Sunda, di mana dalam cara mengolahnya pun harus memanfaatkan media yang berasal dari alam. Jubleug, diambil dari pohon nangka yang lalu diukir menyerupai wadah besar untuk menumbuk padi.

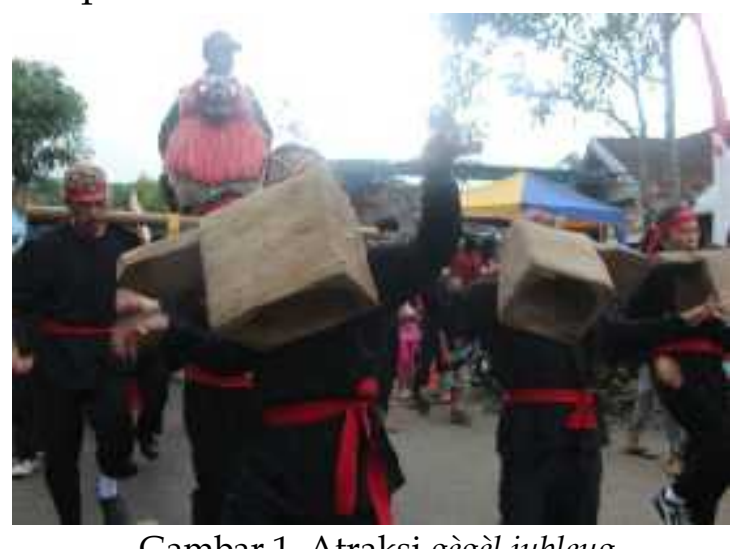

Gambar 1. Atraksi gègèl jubleug

Sumber: Dokumentasi radio RASI FM, 2017

Selain mempersiapkan acara ini, RASI FM pun mendokumentasikan acara dua hari dua malam tersebut melalui siaran radio secara on-air, off-air dan membuat dokumentasi audio-visual. RASI FM sebagai radio komunitas Desa Cisewu berperan sebagai media komunikasi warga dan pemelihara budaya lokal. Kami menguraikan lebih mendalam hasil temuan di lapangan dalam tabel 1. 
Berdasarkan tabel tersebut, kegiatan perekaman terdiri dari kegiatan pengumpulan informasi dan pencatatan. Radio RASI FM memiliki beberapa kru penyiar yang bertugas melakukan kegiatan ini. Pengumpulan informasi dilakukan melalui wawancara pada pelaku budaya ngaruat lembur atau sesepuh desa yang sebelumnya pernah diadakan di Desa Cisewu. Selain itu, wawancara juga dilakukan pada budayawan dan pelaku kesenian tradisional yang akan memeriahkan budaya ngaruat lembur.

Pemilik radio menjelaskan bahwa, "Kita sebelum kegiatan puncak mengumpulkan seniman budayawan lokal, aya rapat heula bahwa kami akan melaksanakan kegiatan ini, siapa yang akan mementaskan kesenian, dan minta sejarahnya [..]" (Latif, wawancara, September 6, 2017). Setelah tahap pertama wawancara dilakukan, tahap kedua wawancara dilakukan pada sebelum kegiatan upacara ngaruat lembur di Balong Sirah pada seniman atau budayawan lokal.

Menurut penuturan pemilik radio,

"Balong sirah teh salah satu sejarah munculna Cisewu. Konon katanya para orang tua kapungkur, karana Cisewu teh awalna ti Balong Sirah. Aya seribu mata air hingga disebat Cisewu. Ci berati cai, sewu berati seribu. Kehidupan masyarakat Cisewu dulu teh kekeringan jeung sajabina. Nah, muncul air dari mata air itu yang mengeluarkan seribu mata air, jadi Cisewu. Balong Sirah mah tempatna. Nu namina sirah mah kan ujung kepala. $\mathrm{Nu}$ pertama ayana cai menurut sejarah di Cisewu nyaeta di Balong Sirah eta. Tah, awalna saurna teh daerah gersang, disebutna ge ciangsara. Sebelum Cisewu teh disebutna ciangsara heula. Ciangsara teh upami dina sunda teh tempat anu sengsara. Karena Cisewu menurut sejarah merupakan buangan warga Tasik atau Sukapura ketika dijajah $k u$ Belanda. Di dieu teh daerahna gersang (di sini daerahnya gersang)" (Latif, wawancara, September 6, 2017).

Balong Sirah menjadi simbol munculnya Desa Cisewu. Air yang dikeluarkan mata air ini merubah Cisewu dari tempat gersang menjadi lahan subur untuk pertanian dan tempat tinggal. Untuk mengucap syukur atas kemajuan Desa Cisewu pada Tuhan Yang Maha Esa maka diadakan syukuran berupa berdoa bersama di Balong Sirah. Hingga sekarang, mata air ini terus memberikan memberikan penghidupan bagi masyarakat Desa Cisewu. Sebagian besar masyarakatnya menggunakan air dari Balong Sirah untuk kegiatan sehari-hari.

Hal ini sejalan dengan pendapat The Press Information Bureau (2009) dalam Sharma and Kashyap (2015) bahwa,

"Community radio stations are expected to serve marginalized sectors, specifically women, farmers, and fishermen; and empower them with information and communication critical for disaster preparedness and management".

Radio komunitas memfasilitasi masyarakat desa untuk menjaga dan melestarikan lingkungan. Pemilik dan penyiar radio berdiskusi bersama masyarakat dalam terselenggaranya acara ngaruat lembur. Masyarakat menjadi bebas mengemukakan pendapat dan pihak Radio RASI FM pun memahami kebutuhan informasi masyarakat desa, contohnya 
dalam pelestarian lingkungan desa. Masyarakat Desa Cisewu rentan terkena bencana longsor akibat pengerukan tanah dan pembabatan hutan di gunung. Tradisi ngaruat lembur menjadi semacam pengingat bagi masyarakat desa untuk lebih menjaga kelestarian lingkungan desa.

Dalam unsur-unsur universal kebudayaan Koentjaraningrat (1985) dalam CMS (2018), tradisi ini termasuk ke dalam "sistem religi dan upacara keagamaan". Tradisi diyakini sebagai penghargaan akan alam. Sesuai kosmologi manusia Sunda, manusia memperlakukan alam sebagai makhluk hidup. Tak salah, bila dalam tradisi ini Masyarakat Desa Cisewu menambah rasa persaudaraan dalam menjaga lingkungan Desa Cisewu yang rentan terjadi bencana.

Setelah terkumpul informasi hasil wawancara, maka dilakukan penuangan hasil wawancara ke dalam tulisan. Tulisan tersebut menjadi bahan informasi siaran yang dilakukan penyiar radio secara on-air dan off-air. On-air ialah kegiatan siaran dalam ruangan dan off-air ialah kegiatan siaran di lokasi kegiatan sedang berlangsung. Selain itu, tulisan ini pun menjadi bahan dalam pelaksanaan dokumentasi audio-visual. Informasi di dalamnya menjadi alur dalam langkah membuat video budaya ngaruat lembur, mulai dari pengambilan gambar dan memasukkan latar suara.

Berdasarkan hasil observasi, kegiatan ini terdiri dari 3 tahap. Pertama, penghimpunan. Penghimpunan di sini berarti penyebaran informasi yang dituangkan dalam bentuk suara dan audiovisual oleh penyiar radio. Diseminasi informasi berbentuk suara berupa siaran langsung dari ruang siaran di Radio RASI FM atau on-air dan siaran di lokasi kegiatan budaya ngaruat lembur atau offair. Kejelasan suara dan gaya penyampaian dari penyiar sangat menentukan tersampaikannya informasi pada pendengar. Informasi tersebut harus sampai pada pendengar yang berada di wilayah pelosok Desa Cisewu. Hal ini ditunjang perlengkapan siaran Radio RASI FM. Walaupun perlengkapan siarannya masih sederhana, namun isi pesan dapat tersampaikan pada pendengar. Begitupun dalam membuat dokumentasi audio-visual oleh penyiar. Mereka menggunakan handycam sebagai alat membuat video.

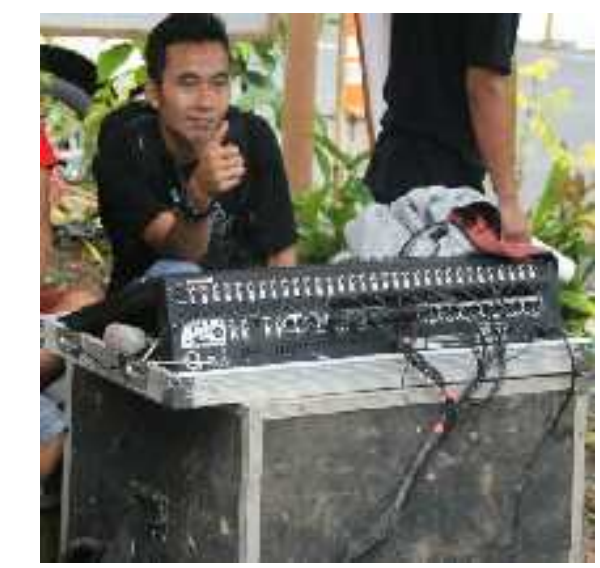

Gambar 2. Siaran off-air tradisi ngaruat lembur Sumber: Dokumentasi radio RASI FM, 2017

Kedua, penyimpanan data. Penyimpanan tulisan hasil siaran disimpan terpisah melalui skrip siaran. Mereka menyimpannya dalam map khusus kegiatan ngaruat lembur sebagai acuan pelaksanaan di tahun berikutnya. Sedangkan penyimpanan data audio-visual disimpan ke dalam media Digital Video Disc (DVD) dan hardisk komputer. Video yang disimpan dalam DVD sebagai dokumentasi suara dan gambar budaya ngaruat lembur yang mengalami pelabelan kemudian ditata dalam rak koleksi radio. Bila data tersebut rusak atau hilang maka disimpan dalam hardisk komputer sebagai backup data. 
Ketiga, pelestarian dokumen. Pelestarian yang digunakan adalah perawatan informasi berbentuk audio-visual. Informasi dalam DVD rawan rusak karena sensitif terhadap goresan. Maka, mereka menyimpan DVD dalam rak paling atas dan dalam laci lemari ruang siaran. Ini dilakukan untuk menghindari goncangan atau goresan dari pemutaran DVD. Perawatan DVD dalam komputer pun hanya sebatas membersihkan virus dalam komputer. Mereka belum sampai pada pembuatan cloud computing sebagai backup data di website.

Berdasarkan hasil temuan di atas, maka digambarkan ke dalam model proses dokumentasi budaya di radio RASI FM, tertuang dalam gambar 3 .

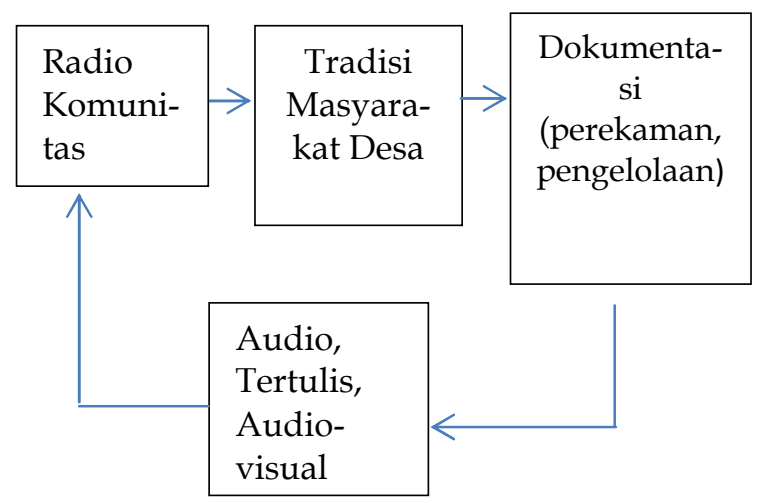

Gambar 3. Model proses dokumentasi budaya Sumber: Hasil penelitian, 2017

Radio komunitas menurut Hollander, Hidayat, and D'haenens (2008), "have established their positions regionally and locally and will continue to do so in the future". Radio komunitas berperan membantu pemerintah untuk membantu masyarakat sebagai wadah aspirasi dan berdiskusi.

Radio komunitas membahas seputar tema atau bidang yang dekat dengan masyarakat, misalnya pendidikan, ekonomi, kesehatan, budaya, lingkungan, hiburan dan lain-lain. Dari tema ini lalu dibuat program-program menarik untuk mengajak masyarakat berpartisipasi. Salah satu tema, yakni budaya. Di Radio RASI FM, budaya dikaitkan dengan tradisi yang selalu dilakukan masyarakat Desa Cisewu, budaya ngaruat lembur.

Budaya ngaruat lembur merupakan kebiasaan dari masyarakat Sunda yang muncul dari kosmologi atau cara pandang masyarakatnya. Kosmologi berarti "ilmu pengetahuan tentang tata dunia atau tata alam semesta" (Sumardjo, 2011). Bila dihubungkan dengan masyarakat Sunda, maka dapat dinamakan kosmologi Sunda. Yakni tata dunia menurut pandangan masyarakat Sunda. Pandangan masyarakat Sunda akan berubah sesuai sejarah keberadaannya.

Begitu pun dengan tradisi ngaruat lembur, yang awalnya diadakan secara tertutup; hanya kalangan sesepuh Desa Cisewu saja menjadi terbuka diikuti semua orang. Radio RASI FM memfasilitasi dan mendiseminasikan tradisi ngaruat lembur pada masyarakat Desa Cisewu dan masyarakat di luar desa. Melalui radio ini, masyarakat mengetahui, menjaga dan melaksanakan pesan dari tradisi ngaruat lembur.

Bila mengikuti tiga Tri tangtu Sunda, dunia terdiri dari, "langit, bumi, dan manusia" (Sumardjo, 2011). Langit bermakna air hujan, bumi sebagai tempat berpijak bergantung pada air hujan dan manusia berada di antara langit dan bumi. Dikaitkan dalam tradisi ngaruat lembur, terkandung makna bahwa langit dan bumi harus dijaga dengan baik. Langit mencurahkan air hujan yang berasal dari bumi. Bila bumi mengalami kerusakan, maka langit pun akan berubah. Manusia yang mendiami bumi dituntut menjaga bumi, misalnya tidak menebang pohon dan merusak ladang. Manusia ha- 
rus menghormati bumi dan langit. Tradisi ngaruat lembur, mengajarkan masyarakat Desa Cisewu untuk bersyukur, sebagai langkah awal menjaga langit dan bumi. Masyarakat Sunda berkomunikasi dengan Tuhan Yang Maha Esa, dirinya sendiri, dengan orang lain, waktu, dan hubungan dengan alam.

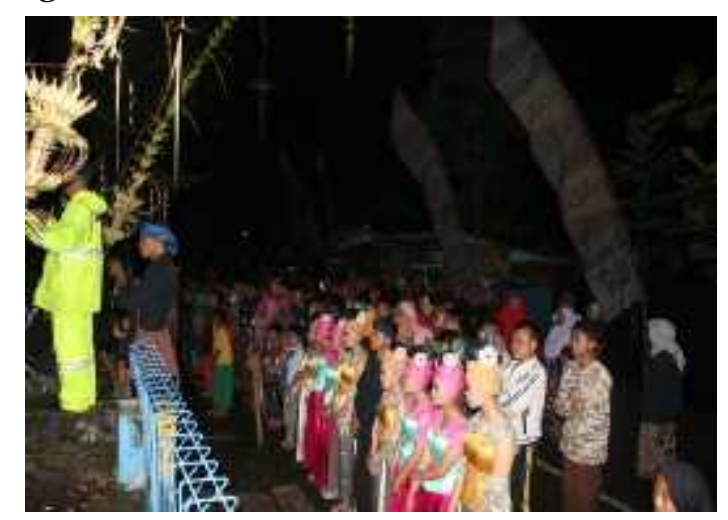

Gambar 4. Berdoa dalam ngaruat lembur Sumber: Dokumentasi radio RASI FM, 2017

Radio RASI FM dalam mengadakan dan menyiarkan budaya ngaruat lembur meliputi kegiatan perekaman dan pengelolaan. Dalam perekaman, tim radio belajar membuka relasi dengan pelbagai masyarakat. Mereka mengumpulkan informasi mengenai tradisi ini ke sesepuh masyarakat, budayawan hingga anggota masyarakat.

Tim radio yang bertugas terdiri dari pemilik radio sekaligus manajer, penyiar sekaligus teknisi dan reporter juga. Radio RASI FM memiliki penyiar sekaligus teknisi berjumlah 2 orang. Walaupun begitu, mereka dapat saling membagi pekerjaan. Hal ini digambarkan bahwa,

"The task for community media therefore is to provide at the community level a platform for articulation and expression of opinions regarding issues relevant to the community; or to help create a local public sphere" (Hollander et al., 2008)
Visi Radio RASI FM ialah dapat menjadi media bagi masyarakat Desa Cisewu dalam mengutarakan pendapatnya mengenai pelbagai hal di masyarakat. Masyarakat sekitar pun menjadi belajar bagaimana berkomunikasi lewat media publik. Ada simbolisme mutualisme terjadi dalam radio komunitas. Apalagi, kehadiran radio komunitas membantu masyarakat yang berada di kampung atau dusun terpencil yang belum memiliki aliran listrik dari pemerintah. Mereka mengetahui informasi baru dari radio yang terpasang menggunakan isi baterai. Setelah anggota tim radio mengumpulkan informasi, mereka mulai mencatat informasi yang telah didapatkannya. Catatan digunakan sebagai bahan skrip siaran dan panduan dalam membuat media audio visual budaya ngaruat lembur. Catatan disusun sebagai salah satu, "Strategies could be understood in terms of 'segmentation'. In short, radio stations design identities 'by imagining and thus partly creating a target audience or segmentation of the Indonesian listener's market" (Manns, 2014).

Tim radio menyusun informasi budaya ngaruat lembur berbentuk skrip menjadi sebuah strategi untuk mendekatkan radio ke masyarakat Desa Cisewu agar memahami kegiatan ini. Secara tidak langsung, tim radio pun menarik segmen radio dari masyarakat luar desa untuk ikut berpartisipasi ke dalam acara budaya ngaruat lembur. Masyarakat yang hadir pun ternyata banyak diikuti oleh masyarakat dari luar Kabupaten Garut, contohnya ada beberapa penginapan terdapat di Desa Cisewu yang khusus menerima pengunjung saat tradisi ini digelar.

Selain itu, tim radio menuangkan informasi budaya ngaruat lembur yang 
didapatkan menjadi catatan dalam alur dokumentasi berbentuk audio visual. Tim radio yang bertugas secara on air dan off air memiliki panduan dalam merekam dan membuat video kegiatan. Dari hal ini, terlihat bahwa Radio RASI FM telah menggunakan beberapa media baru, di antaranya komputer, electronic mail (EMAIL), internet, dan whatsup (WA).

Radio RASI FM menggunakan komputer sebagai media siaran dan media pengolahan data yang hanya berjumlah satu. Electronic mail (EMAIL) digunakan tim Radio RASI FM sebagai perrtukaran pesan antara tim radio dengan masyarakat dan pihak luar radio. Dalam penggunaan internet, tim radio masih mendapatkannya melalui fasilitas di handphone (HP). Radio belum memiliki fasilitas sendiri internet untuk memudahkan pencarian informasi. Sedangkan dalam penggunaan whatsup (WA), mereka menggunakannya sebagai media komunikasi dalam memudahkan penyampaian pesan saat tradisi ngaruat lembur berlangsung dan kegiatan lainnya.

Radio yang mulai menggunakan media baru di atas, membantu pendengar radio dari luar dan dalam Desa Cisewu menangkap informasi dari Radio RASI FM. Tim radio yang menggunakan media baru secara aktif membantu mengembangkan relasi dari semua kalangan yang pada akhirnya dapat membantu radio menghadapi krisis internal.

Salah satu krisis internal ini ialah masalah teknis dalam fasilitas pemancar siaran radio. Desa Cisewu yang berada di wilayah dataran tinggi rentan terkena petir ketika hujan deras. Radio RASI FM pernah mengalami kerusakan pemancar siaran radio akibat terkena petir hingga tidak berfungsi. Radio tidak dapat siaran hingga beberapa bulan karena masalah dana untuk memperbaiki pemancar siaran radio yang biaya cukup tinggi.

Tapi, hal ini dapat tertangani atas bantuan dari pendengar radio yang bertempat tinggal di luar Desa Cisewu. Melalui komunikasi lewat media baru, dapat membantu tim radio meluaskan jaringan kerjasama ke masyarakat luas. Tak terkecuali, dalam kegiatan tradisi ngaruat lembur. Pelaksanaan kegiatan ini banyak dibantu oleh pemerintah setempat dan masyarakat yang fokus dalam pemeliharaan budaya Sunda.

Walaupun begitu, tim radio belum melakukan penyimpanan dan pelestarian dokumentasi media baru menggunakan media baru. Tim radio belum memiliki pengetahuan dalam memanfaatkan media baru sebagai media dokumentasi. Padahal, hal ini dapat mengurangi biaya produksi siaran Radio RASI FM. Berdasarkan kegiatan perekaman dan pengelolaan yang dilakukan Radio RASI FM dalam tradisi ngaruat lembur, radio sudah membantu masyarakat Desa Cisewu dalam menjaga tradisi desa. Selain itu, hasil dokumentasi dapat dilakukan kembali sebagai acuan pelaksanaan dan pengembangan penyelenggaraan ngaruat lembur tahun berikutnya. Setelah beberapa kali tergelarnya acara ini, maka pihak radio memiliki panduan sendiri dalam pelaksanaannya.

\section{SIMPULAN}

Radio RASI FM sebagai radio komunitas telah melakukan dokumentasi budaya dalam tradisi ngaruat lembur di Desa Cisewu. Dalam proses dokumentasi, mereka menggunakan tahapan perekaman berupa pencarian data penulisan data. Dalam tahap pengelolaan, 
mereka melakukan kegiatan penghimpunan, penyimpanan dan pelestarian dokumen. Hasil dari kegiatan ini terciptanya dokumentasi berupa audio, tertulis, dan audio-visual. Namun, proses dokumentasi yang dilakukan Radio RASI FM belum sampai tahap pelestarian data berbasis digital atau cloud computing padahal hal ini dapat membantu terjaganya informasi dari hasil dokumentasi. Selain itu, rentannya lokasi radio tertimpa bencana longsor dan gempa mengakibatkan data yang sudah terkumpul dan tersimpan di radio bisa hilang. Maka, penggunaan media baru sebagai produk dokumentasi budaya dapat dilakukan tim radio. Hal ini, menjadikan budaya ngaruat lembur kaya dalam tahap pelaksanaan dan penyimpanan dokumentasi kegiatannya.

\section{DAFTAR PUSTAKA}

Baron, R. (2016). Public folklore dialogism and critical heritage studies. International Journal of Heritage Studies, 22(8), 1-19. https:/ / doi.org/10.1080/13527258.20 16.1150320

CMS, S. (2018). Komunikasi dalam dokumentasi: sebuah pengantar tentang dokumentasi budaya (1st ed.). Kebumen: Intishar Publishing.

Desideria, B. (2012). Pendekatan komunikasi partisipatif dalam praktik jurnalisme warga di radio komunitas (Skripsi). Fakultas ISIP. Universitas Atma Jaya, Yogyakarta. Retrieved from http:/ / ejournal.uajy.ac.id/535/2/1KOM0316 7.pdf

Harrison, H., Birks, M., Franklin, R., \& Mills, J. (2017). Case study research: foundations and methodological orientations. FQS (Forum Qualitative Social Social Research), 18(1), 19.
Retrieved

from

http:/ / www.qualitative-

research.net/index.php/fqs/article/ view/2655/4079\#g31

Hollander, E., Hidayat, D. N., \& D'haenens, L. (2008). Community radio in Indonesia. Javnost - The Public, 15(3), 59-74. https:/ / doi.org/10.1080/13183222.20 08.11008976

Kusumohamidjojo, B. (2009). Filsafat kebudayaan: proses realisasi manusia. Yogyakarta: Jalasutra.

Lilis, C. H. D., Yuliati, N., \& Rochim, M. (2013). Mengusung masyarakat madani melalui radio komunitas. MIMBAR, 29(2), 145-154. Retrieved from

https:/ / ejournal.unisba.ac.id/index. php/mimbar/article/view/399/302

Manns, H. (2014). Youth radio and colloquial Indonesian in urban Java. Indonesia and the Malay World, 42(122), 43-61. https:/ / doi.org/10.1080/13639811.20 14.876156

Nuryaman. (2017, September). Mengenal seren taun, ritual tahunan masyarakat adat Sunda Wiwitan Cigugur. PikiranRakyat. Bandung. Retrieved from http://www.pikiranrakyat.com/jawa-

barat/2017/09/14/mengenal-serentaun-ritual-tahunan-masyarakatadat-sunda-wiwitan-cigugur

Purwono. (2010). Dokumentasi. Yogyakarta: Graha Ilmu.

Ramdhan, B. (2015). Evaluasi keanekaragaman hayati tumbuhan dalam heterogenitas spasial: studi kasus Kampung Adat Cikondang Jawa Barat (Tesis). Universitas IPB, Bogor. Retrieved from 
repository.ipb.ac.id/jspui/bitstream /123456789/76719/1/2015bra.pdf

Sedana, I. N., Damayani, N. A., \& Khadijah, U. L. S. (2013). Preservasi berbasis kearifan lokal (studi kasus mengenai preservasi preventif dan kuratif manuskrip lontar sebagai warisan budaya di Kabupaten Klungkung Bali). Kajian Informasi $\mathcal{E}$ Perpustakaan, 1(1), 91-105. https://doi.org/https:/ / doi.org/10. 24198/jkip.v1i1.9616.g4325

Sharma, A. \& Kashyap, S. K. (2015). Community radio: a community media module for empowerment of rural women. Media Asia, 42(3-4),
180-191.

https:/ / doi.org/http:/ / dx.doi.org/1

0.1080/01296612.2016.1142245

Sudarsono, B. (2016). Mепuju era baru dokumentasi. Jakarta: LIPI.

Sumardjo, J. (2011). Sunda: pola rasionalitas budaya. Yogyakarta: Kelir.

Susanti, S., Mulyana, D., \& Damayani, N. A. (2013). Penulis sunda sebagai pelestari budaya. Kajian Informasi $\mathcal{E}$ Perpustakaan, 1(2), 1-26. https://doi.org/https://doi.org/10. 24198/jkip.v1i2.11046.g4947

Whitaker, J. C. \& Mancini, R. K. (2013). Techincal documentation and process. New York: CRS Press. 


\section{DAFTAR TABEL}

Tabel 1

Hasil temuan di lapangan

\section{Dokumentasi Radio RASI FM}

Perekaman 1 . Pengumpulan informasi dilakukan penyiar radio sebelum kegiatan berlangsung

2. Pencatatan berupa penuangan data yang diperoleh untuk menjadi bahan informasi siaran dan alur penyusunan dokumentasi audio visual

Pengelolaan 1. Penghimpunan dilakukan penyiar radio dengan membagi tugas sebagai penyiar secara on-air, penyiar secara off-air, penyiar yang mendokumentasikan audio-visual

2. Penyimpanan berupa menyimpan tulisan hasil siaran di radio dan penyimpanan data ke dalam media audio-visual

3. Pelestarian dokumen berupa pemisahan dan perawatan media audio-visual

Sumber: Hasil penelitian, 2017 